\title{
What Would Your Parents Say? The Impact of Cohabitation Among Young People on Their Relationships with Their Parents
}

\author{
Anna Baranowska-Rataj
}

Published online: 15 October 2013

(C) The Author(s) 2013. This article is published with open access at Springerlink.com

\begin{abstract}
Most European countries have seen a retreat from marriage, which is increasingly preceded or replaced by cohabitation. A question that arises in light of this trend is how the diffusion of non-marital cohabitation may affect the quality of family relations. This article investigates how cohabitation among young people affects their level of satisfaction with their relationship with their parents. We analyse data from the recently released Generation and Gender Survey for Poland, a country with a limited degree of social acceptance of cohabitation, a high degree of attachment to the institution of marriage, and a familialistic culture. Since young adults who choose to cohabit are a rather specific group, we use statistical methods that allow us to control for both the observed and the unobserved characteristics of cohabiters. We find that young people who cohabited in their first union rated their level of satisfaction with their parental relationship lower than their peers who were married. Thus, at least in the context of a country where informal partnerships are not yet fully socially accepted or institutionally supported, the role of cohabitation in intergenerational relations may not be neutral.
\end{abstract}

Keywords Satisfaction with family life - Cohabitation · Intergenerational relations · Adult child-parent relations · Relationship quality

\section{Introduction}

Most European countries have experienced a decline in the rates of marriage, which is increasingly preceded or replaced by cohabitation. Younger generations are more likely to

\footnotetext{
A. Baranowska-Rataj

Institute of Statistics and Demography, Warsaw School of Economics, Madalinskiego 6/8, 02-513 Warsaw, Poland

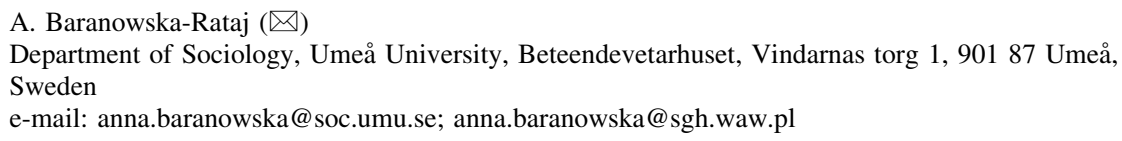


follow these non-traditional paths in life, even in societies that continue to place a very high value on the institution of marriage. According to the recent literature, in countries where cohabitation is not widely accepted, choosing cohabitation as a living arrangement may lead to a deterioration in a young person's relations with his or her family (Di Giulio and Rosina 2007; Schröder 2008). While satisfying family relationships are among the most important sources of happiness, parent-child conflict may substantially reduce wellbeing both among parents and adult children. Thus, the deinstitutionalisation of partnerships among younger cohorts could potentially lead to a decrease in life satisfaction (Dai et al. 2012; Daatland 2007; McIlvane et al. 2007; Lane 2000).

The aim of this study is to gain more insight into the consequences of cohabitation for the quality of intergenerational relations. The family functioning in both early and adult life course stage and the mutual support exchanged between generations is a central issue in research on happiness and life satisfaction (Proctor et al. 2009). However, the impact of an adult child's life choices on the quality of relations with parents has so far hardly been investigated in empirical practice. Recently, this subject has been attracting increasing attention, though. To the best of our knowledge, the existing evidence comes from just five studies. Schröder (2008) provided qualitative evidence on the perceived negative impact of cohabitation on the quality of parental relationships among young people in Italy. ${ }^{1}$ Nazio and Saraceno (2012) found no evidence that cohabitation negatively affected the quality of intergenerational relations, as measured by the frequency of meetings with parents, in Italy and Great Britain. Maslauskaite (2011) showed that there was no significant difference in the frequency of meetings with parents between cohabiting and married children in Lithuania. Daatland (2007) found no difference between cohabiting and married adult children in the quality of their relationships with their parents in Norway. Finally, in the US, Eggebeen (2005) showed that cohabiting couples were less likely to exchange support with their parents than married couples. Clearly, the few available studies provide no consensus on the links between partnership choices among young people and the strength of their bonds with their parents.

Previous studies analysed the quality of relationships between young people and their parents by comparing the adult children who were cohabiting or married at the time of data collection. We take a different approach because we believe that the contemporaneous strength of bonds with parents is not determined by the present marital status of adult children alone. Instead, we consider the role of the union formation choices that might have preceded the current partnership. Hence, rather than focusing solely on the contemporaneous marital status of the adult children, we consider the impact of one of the key life course transitions, i.e. the formation of the first partnership; and distinguish between adult children who cohabited and those who married directly in their first union. At the same time, we control for the current marital status of adult children.

While most of the available studies examined the behavioural aspects of family cohesion and solidarity, such as the frequency of contacts between family members or the intensity of intergenerational transfers, in this paper we focus on the overall level of satisfaction young people report in their relationship with their parents. A similar approach, with a focus on the quality of intergenerational relations as perceived by adult children, was applied in empirical research by Komter and Knijn (2006), but this study did not examine the influence of adult children's living arrangements. Looking at the satisfaction with parental relationship rather than at the behavioural aspects of family cohesion may

\footnotetext{
1 Throughout this paper, "parental relationship" refers to the relationship between a child and his or her parents, not to the relationship between the mother and the father.
} 
yield additional insights into the scientific debate on the quality of intergenerational relations and the way they matter for the individual subjective well-being. Thus, this study may bring us closer to understanding whether recent demographic developments have a negative impact on overall life satisfaction.

We use data from the Polish edition of the Generation and Gender Survey (GGS), which is explicitly designed to investigate the key life course transitions and the quality of intergenerational relations in Europe (Vikat et al. 2008). Data for Poland may be considered very relevant for the research question addressed in this paper, because cohabitation has not yet become a common and socially accepted living arrangement in this country. Unlike in Scandinavian countries, for example, in Poland marriage is still the traditional and most socially supported way to establish a family. Attitudes towards cohabitation are rather ambiguous, largely because, according to the teachings of the dominant Roman Catholic Church, living together without being married is a sin. We can expect to find that, under such conditions, the partnership choices of young people may have a negative impact on their relations with other family members, especially with their parents. We examine this hypothesis by means of a multivariate statistical analysis. Unlike in previous studies, we do not treat cohabitation as an ascribed trait of young people, which is random conditional on other observed characteristics. Instead, we use econometric techniques that take the potential selectivity on unobservable into account. Specifically, we refer to the bivariate probit models that address the situation that occurs when one of the explanatory variables (in our case, the type of union) and the dependent variable (the level of satisfaction with the parental relationship) may be jointly affected by some unobserved characteristics, such as personality traits. We compare the results from standard probit models with the results of bivariate probit models to ensure that our results are consistent.

This paper is structured in the following way. In Sect. 2, we explore the theoretical concepts behind our empirical analyses. In Sect. 3, we explain why Poland may be a relevant case study for the empirical application of these concepts. In Sect. 4, we describe the data employed in this study. In Sect. 5 we provide a description of the methods used. The empirical results are presented in Sect. 6. Finally, in Sect. 7 we provide a summary of the most important findings from this paper, as well as a discussion of the study's limitations and perspectives for future research.

\section{Theoretical Concepts}

There is a long-standing debate about the impact of adult children's life styles and status attainment on the quality of family relations and family members' life satisfaction (Pillemer and Suitor 2002; Proctor et al. 2009). In particular, researchers have stressed the role of the sometimes contradictory norms and expectations that adult children are expected to fulfil in order to maintain a good relationship with their parents. Recent literature has emphasised that when young people make partnership choices that clash with social attitudes and norms, a deterioration in their relations with their parents may occur (Rosina and Fraboni 2004; Di Giulio and Rosina 2007; Schröder 2008). Both the general social expectations regarding the transition to adulthood and the specific norms concerning union formation may be of importance.

Many societies have certain norms regarding the status a person is expected to achieve after reaching some specific age in order to be regarded as an adult. In general, young people are usually expected to complete their education, find a stable job, leave the parental home and establish an independent life; and, ultimately, to become a potential 
source of support for their parents. These social expectations may also include getting married and forming their own family (Liefbroer and Billari 2010). This norm applies specifically to the countries where marriage is very strongly valued. In such countries, young adults who remain unmarried may be regarded as avoiding responsibility and commitments, and their unmarried status may have a negative impact on their relationship with their parents.

The norms that condition adulthood and maturity on marital status may overlap with social attitudes towards living arrangements that are an alternative to marriage, such as cohabitation. These attitudes can be related to religious influences, such as the belief that living in a non-marital relationship is a sin. In societies where, from a moral point of view, marriage is considered the only "proper" route to family formation, and cohabitation is not regarded as an acceptable living arrangement, adult children who cohabit might be seen as failing to respect the rules their parents tried to teach them (Maslauskaite 2011).

Importantly, from a conceptual point of view, the discrepancy between social expectations and the life choices of young adults does not necessarily affect the behavioural aspects of family cohesion. In other words, cohabitation may not translate into a lower frequency of meetings or a decrease in intergenerational support, even if it does produce some ambivalence in relationships. First, behavioural aspects of family cohesion may reflect the impact of norms and social expectations, rather than genuine affection (Kalmijn and Dykstra 2006). Young people may feel obliged to meet with their parents frequently, even if the quality of their relationship with their parents is rather poor. Moreover, the divergence between the norms regarding status attainment by young adults and the actual life course transitions experienced by young people may cause parents to feel more obliged to get involved in their adult children's lives (Pillemer and Suitor 2002). Second, face-toface meetings are not the only means of maintaining contact; recently developed technologies make it easier for family members to stay in touch, and these communication tools are playing an increasingly important role in these relationships as mobility rises and the pace of life becomes faster. Thus, it can appear that young people meet with their parents only sporadically, when in fact they have frequent contact and a good relationship with their parents. Summing up, even if their partnership form has not been accepted by their parents, the behavioural aspects of family cohesion will not reveal any cleavage or ambivalence in the relationship between adult children and their parents. Still, choosing cohabitation may affect the degree of satisfaction young people derive from their relationship with their parents, and may thus have an impact on their quality of life.

\section{Social Acceptance of Cohabitation and the Value of Marriage in Poland}

In some recent international comparisons, Poland has stood out as a country with a low level of social acceptance for cohabitation. For example, Soons and Kalmijn (2009) showed that the average level of social acceptance of a couple living together "under the same roof" without being married is lower in Poland than the European average. Similarly, Vanassche et al. (2012) showed that Poland belongs to the group of countries with a relatively high level of disapproval of alternative family types like cohabitation, and a marked attachment to the institution of marriage. While in many European countries cohabitation has already become a viable and widely accepted alternative to marriage (Kalmijn 2007a; Kiernan 2004), in Poland the onset of the processes that lead to the adoption of more positive social attitudes towards cohabitation has been very recent. 
To provide a more detailed picture of the level of social acceptance for cohabitation, we can look at data from the European Values Survey 2008, which showed that the share of respondents who said they consider it acceptable for a couple to live together without being married was around $61 \%$ in Poland. Clearly, cohabitation is not condemned by the vast majority of Polish society. The share of people in Poland who indicated they accept cohabitation was close to the proportion observed in most Central and Eastern European countries. Nevertheless, the share was definitely smaller than in Western Europe, where it ranged from 75 to $90 \%$; and in Scandinavian countries, where about $95 \%$ of the population surveyed said they consider it acceptable for couples to live together without being married.

The limited degree of social acceptance of cohabitation and the high value placed on marriage may be largely ascribed to the influence of the Roman Catholic Church. According to the teachings of the Church, getting involved in intimate relations of any form that are not "legitimated" by a marriage can be regarded as a sin. According to data collected in the International Social Survey Programme 2008, over $90 \%$ of Poles were raised in the Catholic Church, compared with an average of $49 \%$ in other European countries. Hence, the perception of cohabitation in Polish society may be to some extent related to the teachings of Catholic priests. Another factor that may negatively affect social attitudes towards cohabitation is related to the fact that, in Poland, this living arrangement has until recently been most common among the lower social strata and among people with adverse partnership experiences (Mynarska and Bernardi 2007). The negative gradient in socio-economic status may have created a negative image of cohabitation in Polish society. Indeed, the colloquial expressions describing cohabitation- "to live at a cat's paw" or "to live together with a cycling license", which are the Polish counterparts of the British expression "living over t'brush" - have rather negative connotations, and seem to imply that these relationships are insecure and "not serious" (Mynarska and Bernardi 2007).

While in general the level of social acceptance of cohabitation is lower in Poland than in other European countries, it has been gradually increasing. Younger generations tend to have more positive attitudes towards such living arrangements (Mynarska and Bernardi 2007). Moreover, they are engaging in this form of partnership with increasing frequency. The results presented by Mynarska and Matysiak (2010) showed that, while cohabitation amounted to about $12 \%$ of all unions formed in the first half of the 1,990 s, this percentage had tripled by 2004-2006. Thus, even though younger generations were still more likely to form their first partnership by marrying rather than by cohabitation, the tendency towards the deinstitutionalisation of union formation was evident. Still, it remains an open question whether choosing this form of relationship is neutral with respect to the quality of the relationships young people have with members of the older generation in their families.

\section{Data}

Our analyses draw on data from the Polish GGS carried out in 2010. The survey was conducted by means of face-to-face interviews in a nationally representative sample. The questionnaire was based on the guidelines formulated by the international committee that set up the Generation and Gender Programme (Vikat et al. 2008). The GGS provides very detailed information on life course transitions, particularly on union formation processes, and it is also a valuable source of data on intergenerational relations. 
For the purposes of this study, we used a subsample of the GGS data made up of cohorts born in 1970-1993, i.e. the cohorts who entered adulthood after the collapse of the Iron Curtain. Previous generations might have made different life choices (including choices about the type of union) based on the specific institutional conditions of the socialist regime. For example, housing was subject to state regulation in socialist countries (Matysiak 2011; Horowitz 1991; Szelényi 1987). In the state-controlled distribution of housing units, married couples were given preference relative to unmarried couples or single people (Zeman 2003). Hence, the fact that marriage conferred certain privileges may have affected the partnership choices of older cohorts.

We restricted our attention to those individuals who had formed their first union by the time of the survey, with a union being defined as living together with the partner (regardless of whether the couple were married). Based on information on the formation of the first union, we divided young people into two groups: those who married directly and those who decided to cohabit. Hence, rather than focusing solely on the current marital status of the adult children, we considered the impact of the key life course transition, i.e. the formation of the first partnership. We excluded young people whose parents were no longer alive, because for this group we have no information about their relationship with their parents. Data on respondents with missing information on any of the control variables were deleted to keep the sample sizes consistent across models. In the final sample, there were 2,764 observations available for use in our analysis.

The dependent variable is the self-rated level of satisfaction derived from relationships with parents, as measured by responses to the following a question: "How satisfied are you with the relationship with your father/mother?" The assessments of adult children were coded on a scale from zero to 10 . In the multivariate analysis of this outcome, we used a number of control variables that correspond to the individual characteristics of the young people and to the characteristics of their parents.

First, we controlled for the cohort in which a young person was born (or, in other words, we controlled for the impact of age). We did this for two reasons. First, previous research has shown that the degree of closeness between children and their parents may decline as children get older (Grundy and Shelton 2001). Second, people's level of satisfaction with their relationship with their parents may change as parents reach more advanced ages and need more support from their adult children. Over the course of children's lives, there is a period of disengagement from parents in early adulthood when children become adults and establish their own lives, followed by a period of increasing closeness in mid-life (Rossi and Rossi 1990).

We also controlled for the impact of gender, because previous studies have shown that women place greater importance on close emotional bonds with family members and are more compassionate and altruistic (Lye 1996). As Maslauskaite (2011) has emphasised, because female identity is socially constructed around sustaining kinship, daughters tend to have more frequent and intense contact with their parents than sons. Hence, the gender of adult children may affect the degree of satisfaction they derive from their relationship with their parents.

According to previous studies, lower socio-economic status (as measured by educational attainment and income) is associated with lower levels of satisfaction with family relations (Komter and Knijn 2006). This could be related to the ambiguity of parent-adult child relations when adult children fail to attain the status that is expected of them, i.e. if they fail to become financially independent (Pillemer et al. 2007). Therefore, our set of control variables includes young people's educational attainment (with the following 
categories: tertiary, upper secondary, lower secondary, primary and in education). ${ }^{2}$ For similar reasons, we also included a variable indicating whether respondents were employed, as well as a measure of how young people rated the financial standing of their household (we placed responses to the question of whether the household is able to make ends meet on a six-point scale, which allowed us to distinguish between those who were doing well and those who were experiencing difficulties). Adding the latter measure was important given the high proportion of low-wage workers in Poland (Casali and Alvarez 2010).

In most religious belief systems, there are norms that children should respect their parents. Hence, religious people may be more likely to maintain high-quality relations with their parents. Indeed, empirical research has shown that people who are more religious also claim to have better family relationships (Komter and Knijn 2006). In the Roman Catholic Church, which dominates in Poland, the norm that children should respect their parents is explicitly stated in one of the Ten Commandments. Therefore, we introduced measures of individual religiosity into the models (we distinguished between those who indicated that religion played a "very important" or an "important" role in their lives, and compared them with those who stated that religion was "neither important nor unimportant", "unimportant" or "totally unimportant" to them).

The proximity of the parental home to the current place of residence of a young person is one of the strongest factors affecting intergenerational relations (Maslauskaite 2011). Proximity facilitates frequent contact and the exchange of support, which may also have a positive impact on the overall level of satisfaction with the relationship on both sides (Bengtson and Roberts 1991; Grundy and Shelton 2001). Therefore, we controlled for the time that was needed to commute between these two locations. For young people who actually lived in the same household as their parents, we did not impute a distance amounting to zero, but instead included a separate dummy for this category. The other categories are as follows: a commute of less than $15 \mathrm{~min}$, a commute of between 15 and $30 \mathrm{~min}$ and a commute of half an hour or more.

Finally, we controlled for the time that had passed from age 15 until the union formation, the time since the formation of the first union until the date of the interview and the current union status. The timing of the union formation needs to be considered in the analysis because partnerships that are formed early in life, among people who are still heavily dependent on their parents, may have a different meaning and impact than unions that are established among more mature adults. Partnerships formed early in life may be regarded as resulting from premature decisions, and are less likely to have parental support. The time since the union formation may also moderate the impact of the partnership on the quality of the relationship with the parents. As was noted in (Nazio and Saraceno 2012), individuals in a newly formed partnership may need time to define their own social space, couple-specific customs and social relations; and may therefore have looser contact with their parents. However, once a partnership is well established, these individuals may find this boundary-setting less necessary. The current union status must be controlled for because changes in the marital status of children may change the quality of the relationship

\footnotetext{
$\overline{2}$ Primary education (also named as elementary or basic) is the lowest and obligatory schooling level. Lower secondary education concerns schools offering 2-3 year programmes providing vocational skills needed at the low-skilled worker level. Upper secondary education corresponds to schools that may be completed after graduating from elementary schools and awarding maturity certificate (which is required in order to participate in tertiary education). Tertiary education means completed university (or its counterpart such as a polytechnique or a higher medical school).
} 
with the parents (for example, a transition from cohabitation to marriage may alleviate the conflict with the parents that emerged when the adult child was cohabiting). ${ }^{3}$

Regarding parental characteristics, we included the educational attainment of the parents (with the following categories: tertiary, upper secondary, lower secondary and primary) because numerous theoretical and empirical studies have emphasised the importance of the socio-economic status of parents. First, better educated parents tend to be more involved in caring for their children (King 2003; Lye 1996; Wilcox 2002), which may result in better relations after children have become adults. Second, education approximates social capital, which encompasses the ability to maintain good relationships with family members. Thus, incidences of family conflicts and the severing of family ties may be lower among better educated parents (Kalmijn and Dykstra 2006). Finally, parents with higher socio-economic status are more likely to be able to provide material and nonmaterial assistance to their children (Semyonov and Lewin-Epstein 2001), which may increase feelings of gratitude and thus positively affect the relationship.

We also controlled for parental divorce. There is very well-established evidence on the negative effects of divorce on the relationships between children and parents, especially when it comes to relationships between fathers and their adult daughters (Kalmijn 2012; De Graaf and Fokkema 2007; Tomassini et al. 2004). The effect of divorce has been shown to depend on its timing: a late divorce has a less negative impact than a separation that occurred early in the child's life (Kalmijn 2007b). We therefore distinguished between individuals who were under or over age 15 when their parents divorced.

The means and proportions summarising the characteristics of the young people and their parental background in the sample used in our analyses are presented in Table 1.

Table 1 Description of the sample structure

\begin{tabular}{lll}
\hline & Mean/proportion & Standard deviation \\
\hline Individual characteristics & & \\
Cohort born 1970-75 & 0.25 & 0.43 \\
Cohort born 1975-80 & 0.32 & 0.47 \\
Cohort born 1980-85 & 0.29 & 0.45 \\
Cohort born 1985-90 & 0.13 & 0.34 \\
Cohort born after 1990 & 0.01 & 0.11 \\
Gender & & 0.49 \\
Male & 0.39 & 0.49 \\
Female & 0.61 & \\
Educational attainment & & 0.45 \\
Tertiary & 0.29 & 0.50 \\
Upper secondary & 0.46 & 0.40 \\
Lower secondary & 0.20 & 0.21 \\
Primary & 0.04 & 0.31 \\
In education & 0.10 & \\
\hline
\end{tabular}

\footnotetext{
${ }^{3}$ Note that the GGS data provide information on union status rather than on partners. For example, if we observe an individual who first cohabited and then married, we cannot be sure if he/she married the person with whom he/she previously cohabited.
} 
Table 1 continued

Mean/proportion

Standard deviation

Current labour market status

Employed

0.79

0.41

Not employed

0.21

0.41

Self-rated financial standing of the household

Poor

Good

0.55

0.50

Importance of religion for respondent

Important

0.70

0.46

Not important

0.30

0.46

Time from age of 15 until entry into first union (in years)

Time that passed since formation of first union (in years)

Current civil status

Married

0.84

0.36

Not married

0.16

0.36

Parental characteristics

Parental education

Tertiary

0.15

0.36

Upper secondary

0.38

0.48

Lower secondary

0.34

0.47

Primary

0.13

0.34

Parental divorce until age 15

Parents divorced

Parents did not divorce

0.95

0.22

Commuting distance to parental home

Lives with parents

Distance to parental home $<15 \mathrm{~min}$

0.27

0.44

Distance to parental home 15-30 min

0.36

0.48

Distance to parental home $>30 \mathrm{~min}$

0.27

0.44

$\mathrm{N}$

2,764

Polish GGS data, author's calculations

\section{Methods}

Our analysis proceeded in three steps. First, in order to gain an overall impression of the differences in levels of satisfaction with parental relationships, we compared the mean ranks of the level of satisfaction among cohabiting and married people. We also carried out the Kruskal-Wallis test (Riffenburgh 2005, pp. 287-291) in order to determine whether the differences in these ranks among cohabiters and married were statistically significant. The Kruskal-Wallis test verified the hypothesis that two samples-in our case, a group of individuals who cohabited and a group who married directly-were drawn from the same population. We used a nonparametric test rather than a parametric procedure because the key variable of interest, satisfaction with the parental relationship, was measured on the 
ordinal instead of an interval scale. We also reported the results from a Pearson Chi square test, which is more conservative than the Kruskal-Wallis test in that it assumes that the level of satisfaction with the parental relationship is a variable measured on nominal scale.

In the second step, we referred to the multivariate analysis. We estimated ordered probit models for the level of satisfaction with the parental relationship, while controlling for a range of observed characteristics which tend to differ between young people who cohabit and those who marry. The set of controls included individual-level socio-demographic characteristics, as well as parental characteristics. At this step, we did not control for any unobserved characteristics of the cohabiters, which could be related to how these respondents assessed their level of satisfaction with their relationship with their parents.

In the third step of our analyses, we estimated bivariate probit models that took into account not only all of the observed characteristics of the young people, but also the unobserved factors driving the selectivity of the cohabiters. An example of such unobserved traits is that people who choose cohabitation may have individualistic rather than collectivistic attitudes (Daatland 2007; Nazio and Saraceno 2012), and these attitudes might affect their relations with family members. Moreover, people with a greater propensity for cohabitation may have been raised in more tolerant families in which the parents did not try to interfere with their children's life choices (Rosina and Fraboni 2004; Di Giulio and Rosina 2007). These dimensions of parental background are difficult to capture adequately in the data. Hence, the key explanatory variable and the dependent variable in our analyses may have been jointly determined by factors that cannot be directly measured in our data. In order to account for such potentially relevant characteristics, the standard probit framework could be extended to a bivariate probit model, in which the selection into the group of cohabiters and the outcome variable (i.e. the level of satisfaction with the parental relationship) are modelled jointly, while allowing for a correlation in error terms in these equations. Such an approach has been applied in various areas, including in psychology and research on health issues (Dickerson et al. 2012; Dawson and Dobson 2010), as well as in research on subjective well-being (Selezneva 2010). Previous studies have usually applied models with either two binary variables or two ordered variables. In our case, the model for choices of the type of union was estimated simultaneously with the model for the level of satisfaction with the parental relationship. Thus, the first equation includes a binary outcome variable and the second equation involves an ordered binary outcome variable. ${ }^{4}$

We estimated jointly the equations for choices of union type and the consequences of these choices in terms of the level of satisfaction with the parental relationship using the full-information maximum likelihood estimation (FIML) algorithm. Our use of the bivariate probit model relied on the routine developed by Sajaia (2008). Following the notation of (Sajaia 2008), we assumed that a propensity to choose cohabitation and the level of satisfaction with the parental relationship are latent variables, denoted $y_{1}^{*}$ and $y_{2}^{*}$, respectively:

$$
\begin{gathered}
y_{1 i}^{*}=x_{1 i} \beta_{1}+\varepsilon_{1 i} \\
y_{2 i}^{*}=x_{2 i} \beta_{2}+y_{1 i} \gamma+\varepsilon_{2 i}
\end{gathered}
$$

where subscript $i$ denotes an individual observation, $\beta_{1}$ and $\beta_{1}$ are vectors of unknown parameters, $\gamma$ is an unknown scalar, $\varepsilon_{1}$ and $\varepsilon_{2}$ are the error terms. The error terms were

\footnotetext{
4 This means that our model is a special case of a bivariate ordered probit model, because any binary probit model is a special case of an ordered probit model.
} 
assumed to be distributed as bivariate standard normal with correlation $\rho$, and to be uncorrelated with the explanatory variables. By allowing for the correlation between the error terms $\rho$, we explicitly assumed that there may have been some unobserved factors which jointly affected the choices of union type and the level of satisfaction with the parental relationship; and, through the simultaneous estimation of models for $y_{1}^{*}$ and $y_{2}{ }_{2}$, we captured these influences and provided unbiased estimates of $\gamma$.

The latent variables $y_{1}^{*}$ and $y_{2}^{*}$ correspond to the outcome variables observed in our data: cohabitation in the first union is denoted as $y_{1}$ and the self-rated level of satisfaction with the parental relationship is denoted as $\mathrm{y}_{2}$ :

$$
y_{1 i}=\left\{\begin{array}{lll}
0 & \text { if } & y_{1 i}^{*} \leq \quad c_{11} \\
1 & \text { if } \quad c_{11}<y_{1 i}^{*}
\end{array} \text { and } y_{2 i}=\left\{\begin{array}{c}
0 \quad \text { if } y_{2 i}^{*} \leq c_{21} \\
1 \quad \text { if } c_{21}<y_{2 i}^{*} \\
\ldots
\end{array}\right.\right.
$$

We assumed that the specific values of the cut-offs $c_{11}, c_{21} \ldots c_{2 K}$ are unknown, but that they are ordered; i.e. that they satisfy the condition that $\mathrm{c}_{21}<\mathrm{c}_{22}<\ldots<\mathrm{c}_{2 \mathrm{~K}-1}$. The individual contribution to the likelihood function can be written as:

$$
\begin{aligned}
P\left(y_{1 i}=1, y_{2 i}=k\right)= & \varphi_{2}\left(c_{11}-x_{1 i} \beta_{1}\left(c_{2 k}-\gamma x_{1 i} \beta_{1}-x_{2 i} \beta_{2}\right) \varsigma \tilde{\rho}\right) \\
& -\varphi_{2}\left(c_{10}-x_{1 i} \beta_{1}\left(c_{2 k}-\gamma x_{1 i} \beta_{1}-x_{2 i} \beta_{2}\right) \varsigma \tilde{\rho}\right) \\
& -\varphi_{2}\left(c_{11}-x_{1 i} \beta_{1}\left(c_{2 k-1}-\gamma x_{1 i} \beta_{1}-x_{2 i} \beta_{2}\right) \varsigma \tilde{\rho}\right) \\
& -\varphi_{2}\left(c_{10}-x_{1 i} \beta_{1}\left(c_{2 k-1}-\gamma x_{1 i} \beta_{1}-x_{2 i} \beta_{2}\right) \varsigma \tilde{\rho}\right)
\end{aligned}
$$

where $\varphi$ is the bivariate standard cumulative distribution function, $\varsigma=\frac{1}{\sqrt{1+2 \gamma \rho+\gamma^{2}}}$ and $\tilde{\rho}=\varsigma(\gamma+\rho)$. If the coefficient for the correlation of error terms $\rho$ is negative (positive), the model suggests that the individuals who chose cohabitation rated their level of satisfaction with their parental relationship systematically lower (higher) than those who were married, due to the influence of some unobserved characteristics that cannot be captured by the control variables. For example, a positive correlation of error terms in equations for cohabitation and the level of satisfaction with the parental relationship may indicate that young people who were raised in families in which the parents were less engaged in their children's life choices are more likely to cohabit than to marry directly. However, this correlation could be also negative, indicating that some young people have individualistic attitudes that increase their propensity for cohabitation, and also cause them to have looser relationships with their parents. If the correlation of error terms $\rho$ is equal to zero, the model for the level of satisfaction with the parental relationship is simplified to a standard ordered probit model, which can be estimated independently of the model on the choices of union type. We report the results of the Wald tests for the significance of the coefficient for the correlation of error terms, along with the results of tests of all of the other regression coefficients.

We present the results from the first equation for selection into the group of young people cohabiting in the first union in Table 2..$^{5}$ These results indicated that people who were born in younger cohorts, came from better educated and less religious families, and

\footnotetext{
5 This equation was estimated jointly with model 2 and model 4, which are shown in Table 4. But for the sake of clarity of argumentation in Sect. 6, which pertains to the consequences of cohabitation on levels of satisfaction with parental relationships, rather than with determinants of union choices, we discuss the results of the selection equation in this section.
} 
Table 2 Results from the probit model on selection into cohabitation

\begin{tabular}{|c|c|c|}
\hline Individual characteristics & Coefficient & SE \\
\hline Female & $-0.23 * * *$ & $(0.05)$ \\
\hline \multicolumn{3}{|l|}{ Cohort (ref. born 1970-75) } \\
\hline Cohort born 1975-80 & $0.31 * * *$ & $(0.07)$ \\
\hline Cohort born $1980-85$ & $0.70^{* * *}$ & $(0.07)$ \\
\hline Cohort born 1985-90 & $0.95^{* * * *}$ & $(0.09)$ \\
\hline Cohort born after 1990 & $1.43 * * *$ & $(0.28)$ \\
\hline \multicolumn{3}{|l|}{ Education attainment (ref. lower secondary) } \\
\hline Tertiary & 0.00 & $(0.09)$ \\
\hline Upper secondary & -0.04 & $(0.07)$ \\
\hline Primary & $0.26 * *$ & $(0.13)$ \\
\hline In education & 0.06 & $(0.09)$ \\
\hline \multicolumn{3}{|l|}{ Parental characteristics } \\
\hline \multicolumn{3}{|l|}{ Parental education (ref. primary) } \\
\hline Tertiary & $0.30 * * *$ & $(0.11)$ \\
\hline Upper secondary & $0.25 * * *$ & $(0.09)$ \\
\hline Lower secondary & 0.08 & $(0.09)$ \\
\hline Parental divorce before age 15 & $0.32 * * *$ & $(0.12)$ \\
\hline \multicolumn{3}{|c|}{ Location of parental home at age 15 (ref. small town) } \\
\hline Metropolitan & $0.21 * * *$ & $(0.06)$ \\
\hline Village & $-0.31 * * *$ & $(0.06)$ \\
\hline Importance of religion in parental home & $-0.44 * * *$ & $(0.06)$ \\
\hline $\mathrm{N}$ & 2,764 & \\
\hline
\end{tabular}

Polish GGS data, author's calculations

$* p<0.05$, ** $p<0.01$, and *** $p<0.001$

were raised in towns rather than in villages, were more likely to be cohabiting in the first union. These findings are consistent with those of previous studies on determinants of union formation. For example, Matysiak (2009) has documented an increasing incidence of cohabitation among younger cohorts. The findings on the selection of cohabiters from better educated families, who can be characterised as more liberal, are in line with the existing literature on union formation processes (Di Giulio and Rosina 2007; Rosina and Fraboni 2004). Moreover, the results concerning the religiosity in the parental home are consistent with previous findings on the impact of religious socialisation and individual religiosity on the choice of cohabitation or marriage (Berghammer 2012; Eggebeen and Dew 2009; Lehrer 2004). Our results also showed that cohabitation was more likely to occur among young people whose parents had divorced; this finding is consistent with the results of previous studies that indicated that the experience of parental divorce may discourage marriage and encourage less binding living arrangements (Kiernan 1992; Sassler et al. 2009). The estimation of a probit model with correction for selection effects (which we used in the third step of our analyses) took all of these characteristics into account. Additionally, a selection model controlled for the unobserved differences between married people and cohabiters, such as differences in the propensity to choose cohabitation that are correlated with the assessment of the level of satisfaction with the parental relationship. 


\section{Results}

A look at the descriptive statistics on the levels of satisfaction young people reported deriving from their relationships with their mother and father presented in Table 3 reveals that those who decided to cohabit tended to rate their levels of satisfaction with these relationships somewhat less favourably than their married counterparts. The average rank of satisfaction with the maternal relationship measured on the scale between 0 and 10 was 8.60 among the cohabiters and 8.81 among the married respondents. Similarly, cohabiters rated their level of satisfaction with their relationship with their father at 7.84, compared to 8.38 among married respondents. The difference in the reported levels of satisfaction with parental relationships is not very large. Still, the results of the Kruskal-Wallis tests and also of the more conservative Pearson's Chi squared led us to reject the hypothesis that the group of cohabiters and the group of married people were the same with respect to the level of satisfaction with the parental relationship.

Obviously, the findings presented above may be confounded by a whole range of factors. As was mentioned in Sect. 5, people who choose cohabitation as the form of their first union differ from those who marry directly, in terms of both individual characteristics and parental background. We should control for these characteristics when we look at the impact of cohabitation on the level of satisfaction with the parental relationship. Moreover, both groups, cohabiting and married, may differ in terms of characteristics that cannot be directly controlled for (such as individualism), but these characteristics may nonetheless affect the quality of their relationships with their parents. We therefore carried out empirical tests of whether a choice to cohabit led to lower quality parental relationships by means of a multivariate statistical analysis. The results from this part of analysis are presented in Table 4 and 5 .

We present separate models for the levels of satisfaction with maternal and paternal relationships. The outcomes of the standard probit models (models 1 and 3) suggested that the association between cohabitation and the level of satisfaction with the maternal relationship was insignificant, but was negative and significant when it came to the paternal relationship. In the selection models (models 2 and 4), we not only controlled for the observed differences between the cohabiting and married groups, but also took into account the potential unobserved characteristics which simultaneously affect the choices of union type and the level of satisfaction with the maternal and paternal relationships. The results from the models actually confirmed rather than contradicted the negative influence of cohabitation on the level of satisfaction with the parental relationship. If we take selectivity of cohabitation into account, it appears that it has a significant negative impact on the level of satisfaction with both the maternal and paternal relationships. Thus, it seems that choosing a non-traditional type of partnership that is not widely accepted in Polish society translates into a lower level of satisfaction with the parental relationship.

The results from the selection models revealed a positive correlation of error terms in the equations for cohabitation and the level of satisfaction with the parental relationship. In speculating about how we should interpret this positive relationship, we could argue that there may be some families in which parents are more tolerant of the life choices of their adult children and therefore tend to maintain good relationships with their children; and that young people from such families may be disproportionately likely to cohabit, rather than to marry directly. ${ }^{6}$ This would be consistent with the patterns of selection driven by the observed characteristics discussed in Sect. 5, where we have shown that young people who were raised in better educated and less religious families, and who live in large cities, displayed a greater

${ }^{6}$ By "disproportionately", we mean "more often than other people with similar observed characteristics". 
Table 3 Distribution of the level of satisfaction with the parental relationship by union type

\begin{tabular}{llllll}
\hline $\begin{array}{l}\text { The rank of satisfaction } \\
\text { measure }\end{array}$ & \multicolumn{2}{l}{$\begin{array}{l}\text { Satisfaction with the maternal } \\
\text { relationship (in \%) }\end{array}$} & & \multicolumn{2}{l}{$\begin{array}{l}\text { Satisfaction with the paternal } \\
\text { relationship (in \%) }\end{array}$} \\
\cline { 2 - 3 } \cline { 5 - 6 } & Marriage & Cohabitation & & Marriage & Cohabitation \\
\hline 0 & 0.52 & 0.58 & 1.87 & 3.05 \\
1 & 0.45 & 0.17 & & 1.16 & 2.15 \\
2 & 0.39 & 0.5 & & 0.26 & 1.65 \\
3 & 0.19 & 0.58 & & 0.71 & 1.4 \\
4 & 0.71 & 0.99 & & 1.42 & 1.98 \\
5 & 4.06 & 5.03 & & 5.22 & 7.26 \\
6 & 3.16 & 3.96 & & 5.22 & 4.7 \\
7 & 6.19 & 8.5 & & 6.89 & 9.16 \\
8 & 17.91 & 18.07 & & 18.49 & 17.74 \\
9 & 13.85 & 15.84 & & 13.08 & 13.37 \\
10 & 52.58 & 45.79 & & 45.68 & 37.54 \\
Total & 100.00 & 100.00 & & 100.00 & 100.00 \\
Mean rank (standard deviation) & $8.81(1.73)$ & $8.60(1.80)$ & $8.38(2.20)$ & $7.84(2.61)$ \\
Pearson's Chi square test & $p=0.019$ & & $p=0.000$ & \\
Kruskal-Wallis test & $p=0.001$ & & $p=0.000$ & \\
$\mathrm{~N}$ & 2,764 & & &
\end{tabular}

Polish GGS data, author's calculations

propensity to enter cohabitation. Better educated and more secular parents who live in large cities are indeed regarded as more tolerant and liberal in the demographic literature (Rosina and Fraboni 2004; Di Giulio and Rosina 2007). Nevertheless, these three variables_-parental education, religiosity, and whether the young person was socialised in a rural or an urban area-clearly do not capture all of the aspects that jointly determine the choice of an "unconventional" type of union and the relationship with the parents. Therefore, the standard probit models presented in Table 4 and 5 appear to have understated the genuine impact of cohabitation on the relationship between adult children and their parents. However, the models that corrected for the selectivity of cohabiters with respect to the unobserved characteristics showed a stronger negative influence.

Regarding the impact of the control variables, we note that the younger cohorts had better relationships with their parents than their older peers. Gender was shown to have affected the level of satisfaction with the parental relationship in a way that is consistent with findings from previous studies (Lye 1996; Maslauskaite 2011): women reported higher levels of satisfaction with their parental relationships than men. Young people with low educational attainment and those who were still in education reported lower levels of satisfaction with their parental relationships than those who had completed tertiary or secondary education. Moreover, although the current employment situation of parents had no impact on relations with parents, the level of satisfaction with the parental relationship was found to have been affected by the financial situation of the household in which the young people lived: those who assessed their material situation as poor were more likely to rate the quality of their relationship with their parents as rather low. These results are in line with the conclusions reached by Komter and Knijn (2006), who also found that the socio-economic status attainment of adult children affected the quality of their relationship with their parents. 
Table 4 Level of satisfaction with the maternal relationship—results from ordered probit models

\begin{tabular}{|c|c|c|c|c|}
\hline & \multicolumn{2}{|c|}{ Model 1—standard probit } & \multicolumn{2}{|c|}{ Model 2-selection model } \\
\hline & Coefficient & SE & Coefficient & SE \\
\hline First union: cohabitation (ref. marriage) & -0.07 & $(0.05)$ & $-0.82 * * *$ & $(0.17)$ \\
\hline \multicolumn{5}{|l|}{ Individual characteristics } \\
\hline \multicolumn{5}{|l|}{ Cohort (ref. born 1970-75) } \\
\hline Cohort born $1975-80$ & 0.05 & $(0.09)$ & 0.13 & $(0.09)$ \\
\hline Cohort born $1980-85$ & 0.22 & $(0.15)$ & $0.41 * * *$ & $(0.15)$ \\
\hline Cohort born 1985-90 & 0.26 & $(0.22)$ & $0.52 * *$ & $(0.21)$ \\
\hline Cohort born after 1990 & $0.62 *$ & $(0.33)$ & $1.00 * * *$ & $(0.33)$ \\
\hline Female (ref. male) & $0.29 * * *$ & $(0.05)$ & $0.21 * * *$ & $(0.05)$ \\
\hline \multicolumn{5}{|l|}{ Educational attainment (ref. lower secondary) } \\
\hline Tertiary & -0.00 & $(0.08)$ & 0.02 & $(0.07)$ \\
\hline Upper secondary & 0.02 & $(0.06)$ & 0.02 & $(0.06)$ \\
\hline Primary & $-0.20 *$ & $(0.11)$ & -0.11 & $(0.11)$ \\
\hline In education & $-0.13^{*}$ & $(0.07)$ & -0.10 & $(0.07)$ \\
\hline Currently working (ref. not working) & -0.02 & $(0.06)$ & -0.02 & $(0.05)$ \\
\hline Poor household's standing (ref. good) & $-0.17 * * *$ & $(0.05)$ & $-0.15^{* * *}$ & $(0.04)$ \\
\hline Time from age of 15 until entry into first union & $0.04 * *$ & $(0.02)$ & $0.04 * * *$ & $(0.01)$ \\
\hline Time since formation of first union & 0.01 & $(0.01)$ & 0.01 & $(0.01)$ \\
\hline Currently married (ref. not married) & -0.03 & $(0.07)$ & -0.05 & $(0.07)$ \\
\hline Importance of religion (ref. low) & $0.21 * * *$ & $(0.05)$ & $0.12 * *$ & $(0.05)$ \\
\hline \multicolumn{5}{|l|}{ Parental characteristics } \\
\hline \multicolumn{5}{|l|}{ Parental education (ref. primary) } \\
\hline Tertiary & -0.00 & $(0.09)$ & 0.14 & $(0.10)$ \\
\hline Upper secondary & -0.05 & $(0.08)$ & 0.07 & $(0.08)$ \\
\hline Lower secondary & -0.01 & $(0.07)$ & 0.04 & $(0.07)$ \\
\hline Parental divorce (ref. no divorce) & $-0.40 * * *$ & $(0.09)$ & $-0.27 * * *$ & $(0.10)$ \\
\hline \multicolumn{5}{|l|}{ Location of parental home (ref. distance $>30 \mathrm{~min}$ ) } \\
\hline Lives with parents & $0.28 * * *$ & $(0.08)$ & $0.26^{* * * *}$ & $(0.08)$ \\
\hline Distance to parental home $<15 \mathrm{~min}$ & $0.21 * * *$ & $(0.06)$ & $0.19 * * *$ & $(0.06)$ \\
\hline Distance to parental home $15-30 \mathrm{~min}$ & 0.01 & $(0.06)$ & 0.02 & $(0.05)$ \\
\hline Correlation of error terms & & & $0.51 * * *$ & $(0.13)$ \\
\hline Threshold 1 & $-1.88^{* * *}$ & $(0.38)$ & $-1.95 * * *$ & $(0.35)$ \\
\hline Threshold 2 & $-1.71 * * *$ & $(0.37)$ & $-1.79 * * *$ & $(0.35)$ \\
\hline Threshold 3 & $-1.55^{* * *}$ & $(0.37)$ & $-1.64 * * *$ & $(0.35)$ \\
\hline Threshold 4 & $-1.46^{* * *}$ & $(0.37)$ & $-1.54 * * *$ & $(0.35)$ \\
\hline Threshold 5 & $-1.28 * * *$ & $(0.37)$ & $-1.38 * * *$ & $(0.35)$ \\
\hline Threshold 6 & $-0.78 * *$ & $(0.37)$ & $-0.91 * * *$ & $(0.35)$ \\
\hline Threshold 7 & -0.55 & $(0.37)$ & $-0.69 * *$ & $(0.35)$ \\
\hline Threshold 8 & -0.21 & $(0.37)$ & -0.37 & $(0.35)$ \\
\hline Threshold 9 & 0.37 & $(0.37)$ & 0.18 & $(0.35)$ \\
\hline Threshold 10 & $0.76^{* *}$ & $(0.37)$ & 0.54 & $(0.35)$ \\
\hline Log likelihood & $-4,110.70$ & & $-5,770.52$ & \\
\hline $\mathrm{N}$ & 2,764 & & 2,764 & \\
\hline
\end{tabular}

Polish GGS data, author's calculations

$* p<0.05$, ** $p<0.01$, and *** $p<0.001$ 
Table 5 Level of satisfaction with the paternal relationship-results from ordered probit models

\begin{tabular}{|c|c|c|c|c|}
\hline & \multicolumn{2}{|c|}{ Model 3-standard probit } & \multicolumn{2}{|c|}{ Model 4-selection model } \\
\hline & Coefficient & SE & Coefficient & SE \\
\hline First union: cohabitation (ref. marriage) & $-0.08 *$ & $(0.05)$ & $-0.67 * * *$ & $(0.19)$ \\
\hline \multicolumn{5}{|l|}{ Individual characteristics } \\
\hline \multicolumn{5}{|l|}{ Cohort (ref. born 1970-75) } \\
\hline Cohort born $1975-80$ & 0.10 & $(0.09)$ & $0.17 *$ & $(0.09)$ \\
\hline Cohort born 1980-85 & 0.19 & $(0.15)$ & $0.34 * *$ & $(0.15)$ \\
\hline Cohort born 1985-90 & 0.18 & $(0.21)$ & $0.39 *$ & $(0.22)$ \\
\hline Cohort born after 1990 & $0.63 *$ & $(0.32)$ & $0.92 * * *$ & $(0.32)$ \\
\hline Female (ref. male) & $0.15^{* * *}$ & $(0.05)$ & $0.09 *$ & $(0.05)$ \\
\hline \multicolumn{5}{|l|}{ Educational attainment (ref. lower secondary) } \\
\hline Tertiary & -0.01 & $(0.07)$ & 0.00 & $(0.07)$ \\
\hline Upper secondary & 0.00 & $(0.06)$ & 0.00 & $(0.06)$ \\
\hline Primary & $-0.22 * *$ & $(0.11)$ & -0.16 & $(0.11)$ \\
\hline In education & -0.02 & $(0.07)$ & 0.00 & $(0.07)$ \\
\hline Currently working (ref. not working) & -0.02 & $(0.06)$ & -0.02 & $(0.05)$ \\
\hline Poor household's standing (ref. good) & $-0.16 * * *$ & $(0.04)$ & $-0.15^{* * *}$ & $(0.04)$ \\
\hline Time from age of 15 until entry into first union & $0.04 * *$ & $(0.02)$ & $0.04 * *$ & $(0.01)$ \\
\hline Time since formation of first union & 0.01 & $(0.01)$ & 0.01 & $(0.01)$ \\
\hline Currently married (ref. not married) & 0.08 & $(0.07)$ & 0.07 & $(0.07)$ \\
\hline Importance of religion (ref. low) & $0.25 * * *$ & $(0.05)$ & $0.19 * * *$ & $(0.05)$ \\
\hline \multicolumn{5}{|l|}{ Parental characteristics } \\
\hline \multicolumn{5}{|l|}{ Parental education (ref. primary) } \\
\hline Tertiary & 0.02 & $(0.09)$ & 0.14 & $(0.10)$ \\
\hline Upper secondary & -0.05 & $(0.07)$ & 0.04 & $(0.08)$ \\
\hline Lower secondary & -0.02 & $(0.07)$ & 0.02 & $(0.07)$ \\
\hline Parental divorce (ref. no divorce) & $-1.36 * * *$ & $(0.09)$ & $-1.23 * * *$ & $(0.11)$ \\
\hline \multicolumn{5}{|l|}{ Location of parental home (ref. distance $>30 \mathrm{~min}$ ) } \\
\hline Lives with parents & 0.07 & $(0.08)$ & 0.06 & $(0.07)$ \\
\hline Distance to parental home $<15 \mathrm{~min}$ & $0.12 * *$ & $(0.06)$ & $0.12 * *$ & $(0.06)$ \\
\hline Distance to parental home $15-30 \mathrm{~min}$ & 0.01 & $(0.05)$ & 0.02 & $(0.05)$ \\
\hline Correlation of error terms & & & $0.38 * * *$ & $(0.13)$ \\
\hline Threshold 1 & $-1.51 * * *$ & $(0.36)$ & $-1.59 * * *$ & $(0.35)$ \\
\hline Threshold 2 & $-1.23 * * *$ & $(0.36)$ & $-1.32 * * *$ & $(0.35)$ \\
\hline Threshold 3 & $-1.12 * * *$ & $(0.36)$ & $-1.21 * * *$ & $(0.35)$ \\
\hline Threshold 4 & $-1.00 * * *$ & $(0.36)$ & $-1.10 * * *$ & $(0.35)$ \\
\hline Threshold 5 & $-0.85^{* *}$ & $(0.36)$ & $-0.96^{* * *}$ & $(0.35)$ \\
\hline Threshold 6 & -0.46 & $(0.36)$ & $-0.58^{*}$ & $(0.35)$ \\
\hline Threshold 7 & -0.23 & $(0.36)$ & -0.36 & $(0.35)$ \\
\hline Threshold 8 & 0.05 & $(0.36)$ & -0.09 & $(0.35)$ \\
\hline Threshold 9 & 0.58 & $(0.36)$ & 0.42 & $(0.35)$ \\
\hline Threshold 10 & $0.93 * * *$ & $(0.36)$ & $0.76 * *$ & $(0.35)$ \\
\hline Log likelihood & $-4,726.33$ & & $-6,388.60$ & \\
\hline $\mathrm{N}$ & 2,764 & & 2,764 & \\
\hline
\end{tabular}

Polish GGS data, author's calculations

$* p<0.05, * * p<0.01$, and $* * * p<0.001$ 
Moreover, our results corroborate the finding of Komter and Knijn (2006) that religious adult children were more likely to maintain high-quality relations with their parents.

The adult children who formed their first union later in life appeared to be more satisfied with their relationship with their parents. The amount of time that had passed since the formation of the union did not seem to have had a significant impact on the quality of relationship with the parents. Somewhat surprisingly, the results also showed that the current marriage status also had no significant effect. This suggests that making the transition from cohabitation to marriage did not necessarily resolve any conflicts that might have arisen when adult children started cohabiting.

The level of satisfaction with the parental relationship was found to be determined not only by the characteristics of the young adults, but also by the parental characteristics. Specifically, parental divorce turns out to be an important factor that negatively affects adult children's level of satisfaction with their relationship with their parents. In line with previous studies (Lye 1996), we found that the relationship between an adult child and his or her father was especially likely to be poor if the parents were divorced. The distance to the parental home was also shown to be strongly associated with the level of satisfaction with the parental relationship. Those young people who had the longest commutes to their parents' place of residence reported lower levels of satisfaction with their relationship with their parents than those who either shared a home with their parents or who had a short commute. These results are also consistent with previous research showing that the proximity of the parental home to the adult child's current place of residence made a difference in the overall level of satisfaction with the relationship from both sides (Bengtson and Roberts 1991; Grundy and Shelton 2001). Parental education attainment did not significantly affect the quality of the relationship between adult children with their parents.

\section{Conclusion}

Recent studies have emphasised that, in countries where the level of social acceptance of cohabitation is low and the value placed on marriage is high, choosing to cohabit may lead to a reduction in the amount of emotional and material support received from the family (Di Giulio and Rosina 2007; Schröder 2008). Nevertheless, even in such countries, including Poland, the youngest generations are increasingly choosing to cohabit when forming partnerships (Mynarska and Bernardi 2007; Matysiak 2009). The question addressed in this paper pertains to the way in which the diffusion of cohabitation-which is among the most important demographic developments observed in many European countries - may affect the quality of relations between young people and their parents. We wanted to find out whether an increasing incidence of cohabitation was having an impact on levels of satisfaction with family life, which is one of the most important dimensions used to assess the quality of life.

We used data from the most recent Polish Generation and Gender Survey in order to examine the influence of cohabitation among young people on the level of satisfaction they felt in their relationship with their parents. Our results confirmed that cohabitation reduces the satisfaction derived from the parental relationship. This conclusion was supported by the results from multivariate analyses that controlled for both the observed and the unobserved characteristics that differ between cohabiters and married people. Our findings suggested that the demographic changes related to union formation patterns in modern societies may lead to deterioration in the quality of the relationships between the generations, especially in countries where cohabitation is becoming increasingly 
common as a living arrangement, but has not yet been fully accepted as a union type equal to marriage.

Obviously, this study has a number of limitations that could be resolved in future research. First, we looked at the impact of cohabitation on adult child-parent relations from the perspective of the younger generation. It would be interesting to find out how parents assess their relationships with children who make such "unconventional" life choices. Second, it would be important to investigate how the influences shown in this study evolve across the life course, as the parents of young adults reach advanced ages. Will the observed cleavages tend to accumulate or diminish? How would this affect the level of support the elderly receive from their adult children? These questions could not be addressed in our study, and should be investigated in future research.

Another limitation of this study is related to the cross-sectional nature of the data at our disposal. The contemporaneous level of satisfaction with the parental relationship is not just a function of the present characteristics of individuals and their parents. Instead, the quality of these relations evolves over time. All of the events that take place starting in early childhood may potentially affect an adult child's current level of satisfaction with his or her parental relationship. While some of these crucial past events have been taken into account in this study (e.g. parental divorce), many events would have remained unobserved and could not be controlled for in the analyses. Ideally, we would be able to follow individuals over time and take repeated measures of the quality of their relations with their parents. This shortcoming of the present study could be addressed in future research if we have available panel data which follow individuals from early childhood up to more advanced ages, and which also include detailed information on the quality of intergenerational relations.

Finally, in the present study we have focused on a single country where we would expect to find a relatively strong, negative relationship between cohabitation and adult child-parent relations. It would be useful to carry out a study with a cross-country comparative perspective in order to investigate to what extent the magnitude of this negative relationship can be mediated by the social and institutional contexts. Drawing on harmonised data from a multitude of countries, it may be possible to find out whether the tensions between cohabiting young adults and their parents become negligible as the level of social acceptance of "non-traditional" living arrangements increases.

Acknowledgments This paper was prepared within the research project "Family Change and Subjective Well-Being" (FAMWELL), which is financed by the National Centre for Research and Development, under the Program Leader. I would like to thank Anna Matysiak, Monika Mynarska, Marta Styrc, Anna Rybińska and the participants of the conference "Family change in Poland from demographic perspective", which was organised by the Demographic Committee of the Polish Academy of Sciences in Warsaw, October 2012, for their valuable comments and suggestions. I would like to express my gratitude to the anonymous reviewers assigned by the Journal of Happiness Studies for their insightful comment on the previous version of the paper. I would like to thank for the support and hospitality that I received during my research stay at Department of Sociology, Umeå University, where the final version of this paper has been revised.

Open Access This article is distributed under the terms of the Creative Commons Attribution License which permits any use, distribution, and reproduction in any medium, provided the original author(s) and the source are credited.

\section{References}

Bengtson, V. L., \& Roberts, R. E. (1991). Intergenerational solidarity in aging families: An example of formal theory construction. Journal of Marriage and Family, 53(4), 856-870. 
Berghammer, C. (2012). Family life trajectories and religiosity in Austria. European Sociological Review, 28(1), 127-144.

Casali, S., \& Alvarez, V. (2010). 17\% of full-time employees in the EU are low-wage earners. Statistics in Focus, 3, 1-8.

Daatland, S. O. (2007). Marital history and intergenerational solidarity: The impact of divorce and unmarried cohabitation. Journal of Social Issues, 63(4), 809-825.

Dai, B., Zhang, B., \& Li, J. (2012). Protective factors for subjective well-being in Chinese older adults: The roles of resources and activity. Journal of Happiness Studies, . doi:10.1007/s10902-012-9378-7.

Dawson, P., \& Dobson, S. (2010). The influence of social pressure and nationality on individual decisions: Evidence from the behaviour of referees. Journal of Economic Psychology, 31(2), 181-191.

De Graaf, P. M., \& Fokkema, T. (2007). Contacts between divorced and non-divorced parents and their adult children in the Netherlands: An investment perspective. European Sociological Review, 23(2), 263-277.

Di Giulio, P., \& Rosina, A. (2007). Intergenerational family ties and the diffusion of cohabitation in Italy. Demographic Research, 16(14), 441-468.

Dickerson, J. B., Smith, M. L., Sosa, E., McKyer, E. L., \& Ory, M. G. (2012). Perceived risk of developing diabetes in early adulthood: Beliefs about inherited and behavioural risk factors across the life course. Journal of Health Psychology, 17(2), 285-296.

Eggebeen, D. (2005). Cohabitation and exchanges of support. Social Forces, 83(3), 1097-1110.

Eggebeen, D., \& Dew, J. (2009). The role of religion in adolescence for family formation in young adulthood. Journal of Marriage and Family, 71(1), 108-121.

Grundy, E., \& Shelton, N. (2001). Contact between adult children and their parents in Great Britain 1986-99. Environment and Planning A, 33(4), 685-698.

Horowitz, C. F. (1991). Housing rights versus property rights: Heritage Foundation.

Kalmijn, M. (2007a). Explaining cross-national differences in marriage, cohabitation, and divorce in Europe, 1990-2000. Population Studies, 61(3), 243-263.

Kalmijn, M. (2007b). Gender differences in the effects of divorce, widowhood and remarriage on intergenerational support: Does marriage protect fathers? Social Forces, 85(3), 1079-1104.

Kalmijn, M. (2012). Long-term effects of divorce on parent-child relationships: Within-family comparisons of fathers and mothers. European Sociological Review,. doi:10.1093/esr/jcs066.

Kalmijn, M., \& Dykstra, P. (2006). Differentials in face-to-face contact between parents and their grown-up children. In P. Dykstra, M. Kalmijn, T. Knijn, A. Komter, A. Liefbroer, \& C. Mulder (Eds.), Family solidarity in the Netherlands (pp. 63-88). Amsterdam: Dutch University Press.

Kiernan, K. (1992). The impact of family disruption in childhood on transitions made in young adult life. Population Studies, 46(2), 213-234.

Kiernan, K. (2004). Unmarried cohabitation and parenthood in Britain and Europe. Law and Policy, 26(1), $33-55$.

King, V. (2003). The influence of religion on fathers' relationships with their children. Journal of Marriage and Family, 65(2), 382-395.

Komter, A. E., \& Knijn, C. (2006). The strength of family ties. In P. Dykstra, M. Kalmijn, T. Knijn, A. Komter, A. Liefbroer, \& C. Mulder (Eds.), Family solidarity in the Netherlands (pp. 107-121). Amsterdam: Dutch University Press.

Lane, R. E. (2000). The loss of happiness in market democracies: New Haven: Yale University Press.

Lehrer, E. L. (2004). The role of religion in union formation: An economic perspective. Population Research and Policy Review, 23(2), 161-185.

Liefbroer, A. C., \& Billari, F. C. (2010). Bringing norms back in: A theoretical and empirical discussion of their importance for understanding demographic behaviour. Population, Space and Place, 16(4), 287-305.

Lye, D. N. (1996). Adult child-parent relationships. Annual Review of Sociology, 79-102.

Maslauskaite, A. (2011). Contacts between adult children and their parents in Lithuania: the effects of familial, individual and structural factors. FilosoFija sociologija, 22(4), 348-364.

Matysiak, A. (2009). Is Poland really 'immune' to the spread of cohabitation? Demographic Research, 21(8), 215-234.

Matysiak, A. (2011). Posiadanie własnego mieszkania a rodzicielstwo w Polsce. Studia Demograficzne, 159(1), 37-55.

McIlvane, J. M., Ajrouch, K. J., \& Antonucci, T. C. (2007). Generational structure and social resources in mid-life: Influences on health and well-being. Journal of Social Issues, 63(4), 759-773.

Mynarska, M., \& Bernardi, L. (2007). Meanings and attitudes attached to cohabitation in Poland. Demographic Research, 16(17), 519-554. 
Mynarska, M., \& Matysiak, A. (2010). Diffusion of cohabitation in Poland. Studia Demograficzne, $157-158(1-2), 11-25$.

Nazio, T., \& Saraceno, C. (2012). Does cohabitation lead to weaker intergenerational bonds than marriage? A comparison between Italy and the United Kingdom. European Sociological Review, 29(3), 549-564.

Pillemer, K., \& Suitor, J. J. (2002). Explaining mothers' ambivalence toward their adult children. Journal of Marriage and Family, 64(3), 602-613.

Pillemer, K., Suitor, J. J., Mock, S. E., Sabir, M., Pardo, T. B., \& Sechrist, J. (2007). Capturing the complexity of intergenerational relations: Exploring ambivalence within later-life families. Journal of Social Issues, 63(4), 775-791.

Proctor, C. L., Linley, P. A., \& Maltby, J. (2009). Youth life satisfaction: A review of the literature. Journal of Happiness Studies, 10(5), 583-630.

Riffenburgh, R. H. (2005). Statistics in medicine (2nd ed.). New York: Elsevier.

Rosina, A., \& Fraboni, R. (2004). Is marriage losing its centrality in Italy. Demographic Research, 11(6), $149-172$.

Rossi, A. S., \& Rossi, P. H. (1990). Of human bonding: Parent-child relations across the life course. Hawthorne: Aldine de Gruyter.

Sajaia, Z. (2008). BIOPROBIT: Stata module for bivariate ordered probit regression. Statistical Software Components.

Sassler, S., Cunningham, A., \& Lichter, D. T. (2009). Intergenerational patterns of union formation and relationship quality. Journal of Family Issues, 30(6), 757-786.

Schröder, C. (2008). The influence of parents on cohabitation in Italy: Insights from two regional contexts. Demographic Research, 19(48), 1693-1726.

Selezneva, E. (2010). What makes Russian women (un)happy? A closer look at the family. OsteuropaInstitut Regensburg Working Paper. Regensburg: Institut for East European Studies.

Semyonov, M., \& Lewin-Epstein, N. (2001). The impact of parental transfers on living standards of married children. Social Indicators Research, 54(2), 115-137.

Soons, J. P., \& Kalmijn, M. (2009). Is marriage more than cohabitation? Well-being differences in 30 European Countries. Journal of Marriage and Family, 71(5), 1141-1157.

Szelényi, I. (1987). Housing inequalities and occupational segregation in state socialist cities: Commentary to the special issue of IJURR on East European cities. International Journal of Urban and Regional Research, 11(1), 1-8.

Tomassini, C., Kalogirou, S., Grundy, E., Fokkema, T., Martikainen, P., Van Groenou, M. B., et al. (2004). Contacts between elderly parents and their children in four European countries: Current patterns and future prospects. European Journal of Ageing, 1(1), 54-63.

Vanassche, S., Swicegood, G., \& Matthijs, K. (2012). Marriage and children as a key to happiness? CrossNational Differences in the Effects of Marital Status and Children on Well-Being. Journal of Happiness Studies,. doi:10.1007/s10902-012-9340-8.

Vikat, A., Spéder, Z., Beets, G., Billari, F. C., Bühler, C., Désesquelles, A., et al. (2008). Generations and gender survey (GGS): Towards a better understanding of relationships and processes in the life course. Demographic Research, 17, 389-440.

Wilcox, W. B. (2002). Religion, convention, and paternal involvement. Journal of Marriage and Family, 64(3), 780-792.

Zeman, K. (2003). Divorce and marital dissolution in the Czech Republic and in Austria-The role of premarital cohabitation. Doctoral thesis: Charles University. 